\title{
Efecto de la suplementación con alimentos ricos en ácidos grasos sobre parámetros productivos y composicionales de la leche bovina
}

\author{
Effect of supplementation with food rich in fatty acids \\ on bovine milk performance and composition
}

Fecha recepción: 15 de enero de 2014

Fecha Aprobación: 2 de mayo de 2014 Carlos Eduardo Rodríguez-Molano ${ }^{1}$, Diego Francisco
Gómez-Lara², Mónica Andrea Moyano-Bautista ${ }^{3}$

\begin{abstract}
Resumen
Se evaluó el efecto de la suplementación con alimentos ricos en ácidos grasos sobre los parámetros productivos y composicionales de la leche bovina; se trabajó con 15 vacas raza Holstein, multíparas, que cursaban el segundo tercio de lactancia. Los animales se dividieron en grupo control, grupo $1 \mathrm{y}$ grupo 2; se formularon tres dietas con contenidos de proteína cruda del $16 \%$ y 1,73 Mcal ENL; se fijaron 7 días de acostumbramiento y 83 días de ensayo; se evaluó producción $(\mathrm{kg})$, grasa $(\%)$, proteína $(\%)$, sólidos no grasos, lactosa $(\%)$ y densidad $(\mathrm{g} / \mathrm{ml})$, mediante el analizador integral de leches Lactoscan ${ }^{\circledR}$. Las dietas están compuestas por un alimento base y por el suplemento a probar, que se agregó en cantidades de acuerdo con su participación máxima para rumiantes; los alimentos base fueron harina de alfalfa, harina de arroz, salvado de trigo, melaza y premezcla mineral, y los suplementos a probar fueron torta de soya y grasa protegida. Se utilizó un diseño
\end{abstract}

\begin{abstract}
The effect of supplementation with food rich in fatty acids on bovine milk performance and composition was evaluated. We worked with 15 Holstein cows, multiparous, on the second third of lactation. The animals were divided into control group, group 1 and group 2. We formulated three diets containing $16 \%$ crude protein and 1,73 Mcal ENL, and set 7 days for habituation and 83 for trial. We evaluated production $(\mathrm{kg})$, fat $(\%)$, protein $(\%)$, non-fat solids, lactose $(\%)$ and density $(\mathrm{g} / \mathrm{ml})$ using the integral Lactoscan ${ }^{\circledR}$ milk analyzer. The diets consist of a staple food and the supplement to try that was added in amounts according to the maximum participation for ruminants. The staple food were alfalfa meal, rice flour, wheat bran, molasses and mineral premix, and the supplements to try were soybean meal and protected fat. We used a completely randomized experimental design and compared the data with the repeated measures ANOVA in $R$ ( $v$. i386). The results
\end{abstract}

1 M.Sc. Universidad Pedagógica y Tecnológica de Colombia (Tunja - Boyacá, Colombia).carlos.rodriguez@uptc. edu.co.

2 Profesional Independiente (Tunja - Boyacá, Colombia).

3 Profesional Independiente (Tunja - Boyacá, Colombia). 
completamente al azar, y los datos se compararon aplicando un ANOVA de medidas repetidas con $\mathrm{R}$ (v. i386). Los resultados revelan que la producción de leche aumentó significativamente $(p \leq 0.05)$ tras la suplementación con torta de soya y grasa protegida, frente a la que se alcanzó en el grupo control. En conclusión, es posible incrementar la producción (kg/día), sin embargo, no mejoraron los parámetros composicionales de la leche, posiblemente, como consecuencia de la alteración metabólica que pudiese presentarse tras la fermentación ruminal de las grasas y la alteración de la síntesis mamaria de los ácidos grasos.

Palabras clave: Torta de soya, Grasa protegida, Holstein. show that milk production increased significantly $(p \leq 0.05)$ after supplementation with soybean meal and fat protected reached in the control group. Although it is possible to increase production (kg/ day), the milk composition parameters did not improve, possibly due to the metabolic abnormality that may occur after ruminal fermentation of fats, and the alteration of the fatty acids mammary synthesis.

Keywords: Soybean meal, Protected fat, Holstein. 


\section{Introducción}

La incapacidad comercial de muchos de los productos finales de la leche (quesos, yogurt, kumis) corresponde a una baja disponibilidad de insumos de buena calidad y de buenos rendimientos productivos; por este motivo, es importante revaluar el renglón que ocupa la leche, al ser un sector relativamente extenso dentro de la geografía nacional, y por su importancia como base económica de muchas familias que subsisten de su producción. Una de las causas que provoca una baja calidad composicional de la leche y sus derivados es la utilización de sistemas de alimentación deficientes, que no nutren al animal $y$, por ende, no cobijan cabalmente los procesos metabólicos que permiten aumentar la calidad de los componentes de la leche, tales como la proteína, las grasas y los sólidos no grasos, parámetros esenciales para la fabricación de derivados de la industria láctea.

El uso de sustancias lipídicas protegidas de la fermentación ruminal surge como un desafío para la alimentación de vacas de muy alto nivel productivo, las cuales entran con facilidad en un profundo balance energético negativo luego del parto (1). La suplementación con lípidos sobrepasantes incrementa la densidad energética de la dieta en este tipo de vacas, sin los riegos metabólicos que implica el uso intensivo de grandes cantidades de granos. Para vacas de alta producción, las experiencias llevadas a cabo tanto en Argentina como en Estados Unidos parecen indicar que con lípidos apropiadamente protegidos de la biohidrogenación ruminal, y controlando los efectos negativos de los lípidos sobre la fermentación ruminal de la fibra, es posible obtener respuestas significativas tanto en producción como en composición química de leche.

\section{Materiales y Métodos}

El estudio se desarrolló en la Granja Experimental "Tunguavita", de la Universidad Pedagógica y Tecnológica de Colombia (UPTC), ubicada en el municipio de Paipa (Boyacá), entre octubre y diciembre del 2013.

Se trabajó con 15 vacas de raza Holstein, multíparas, que cursaban el segundo tercio de lactancia. El total de los animales se dividió aleatoriamente en tres grupos experimentales, sobre los que se probaron igual número de dietas. Las vacas se manejaron en el hato, bajo el sistema de rotación de praderas que estaban compuestas por kikuyo (Pennisetumclandestinum) y trébol rojo (Trifolium pratense L.), en una proporción 60:30, con rotación de 55 días, suministrado en forma colectiva y ofrecido en fresco (pastoreo).

Dietas. Se formularon tres dietas con contenidos de proteína cruda del $16 \%$ y $1,73 \mathrm{Mcal}$ del NEL/Kg. Las dietas están compuestas por alimentos base y por el suplemento a probar, que se agregó en cantidades de acuerdo con su participación máxima para rumiantes (Tabla I). La grasa protegida se suministró a razón de $650 \mathrm{~g} / \mathrm{animal} / \mathrm{d}$ ía, dividida en el ordeño de la mañana y la tarde (325 g/animal/ordeño); no se tuvo en cuenta en el balanceo de la ración, ya que esta no aporta proteína, sin embargo, se tuvo en cuenta para el balanceo de la energía.

La cantidad suministrada a las vacas de la ración totalmente mezclada fue de $2 \mathrm{~kg} / \mathrm{d}$ ía ( $1 \mathrm{~kg} /$ ordeño), con base en los requerimientos de mantenimiento y producción de cada animal, de acuerdo con lo recomendado por el NRC (2).

Tabla I. Participación de cada ingrediente en las dietas (\% de materia seca).

\begin{tabular}{llll}
\hline Ingrediente & Dieta 1 Control (C) & Dieta 2 Torta de soya (TS) & $\begin{array}{c}\text { Dieta 3 Grasa protegida }{ }^{\circledR} \\
(\mathrm{GBP})\end{array}$ \\
Harina de alfalfa & 51 & 12 & 48 \\
Harina de arroz & 21 & 28 & 19 \\
Salvado de trigo & 18 & 25 & 18 \\
Melaza & 10 & 10 & 5 \\
Premezcla mineral* & 5 & 5 & \\
Torta de soya & 0 & 20 & $(650$ g/día/animal) \\
Grasa protegida & 0 & &
\end{tabular}


El estudio tuvo una duración de 90 días: 7 de acostumbramiento y los restantes 83 de experimentación. Los parámetros evaluados fueron: a) Producción de leche diaria, (kg/ día), producto de la sumatoria del ordeño de la mañana y tarde; estos datos fueron organizados según la identificación de cada animal y la dieta suministrada, consolidándose un promedio semanal para cada grupo, siendo corregida al $4 \%$ de grasa mediante la fórmula $\mathrm{FCL}=0.4 \times \mathrm{kg}$. de leche $+15 \times \mathrm{kg}$ grasa (3). b) Calidad composicional de la leche (\% proteína, densidad $\mathrm{g} / \mathrm{ml}$, \% grasa, $\%$ sólidos no grasos.); se recolectaron muestras de $40 \mathrm{ml}$ leche/vaca cada 2 días, registrando la media semanal por cada grupo en cuestión; esta leche fue empacada en recipientes debidamente rotulados; transportándolos a una temperatura de $4{ }^{\circ} \mathrm{C}$. El análisis de las muestras se realizó por medio del Analizador integral de leche Lactoscan ${ }^{\circledR}$, previamente calibrado y comparado con métodos estandarizados (4). Se manejó un diseño completamente al azar, aplicándose un ANOVA de medidas repetidas con Ri386.

\section{Resultados y Discusión}

Se observa un aumento en la producción de leche en las dietas T2 y T3, con respecto a la dieta control. Según Schneider et al. (1988), los efectos en la inclusión de $0,5 \mathrm{~kg}$ de grasa produjo un incremento del $9,12 \%$ y el $11 \%$ en producción de leche en hatos de Holstein y Jersey, respectivamente, con una diferencia promedio de 1,94 kg de leche entre los animales con y sin acceso a la grasa; tras la suplementación también ser reportan aumentos entre 0,45 y 0,77 $\mathrm{kg} / \mathrm{día}$, que han sido ampliamente informados en la literatura con animales estabulados y bajo condiciones templadas, con incrementos de 1,2 y $1,7 \mathrm{~kg}$ leche/animal/día; y $2,8 \mathrm{~kg}$ con suplementos altos en proteína (5). Otros estudios mencionan un aumento en la producción de leche de vacas alimentadas con sales de calcio de ácidos grasos de cadena larga en la lactancia temprana; resultados similares fueron hallados por Schneider (1988).

Palmquist (7) obtuvo, al adicionar $0,5 \mathrm{~kg}$ de grasa, un aumento en la producción de leche hasta del $10 \%$. Cuando fue añadida un $5 \%$ de grasa a dietas al comienzo de la lactación, como soya integral tostada (6) o grasa by-pass en forma de "prills", la producción de leche fue más baja que la de los controles hasta las 5 o 6 semanas de lactación, respectivamente, lo que pareció deberse al menor consumo de materia seca de las dietas suplementadas con grasa. El contenido de grasa no fue diferente entre T1, T2 y T3, pero fue mayor en la dieta control con respecto a la dieta con inclusión de grasa protegida.

Los resultados alcanzados coinciden con los observados al evaluar los efectos de la suplementación con sales de calcio sobre la digestión ruminal en vacas lecheras en pastoreo (1), en donde se mencionan valores para porcentaje de grasa de $3,2 \%, 2,6 \%$ y $2,6 \%$ para los tratamientos control, torta de soya y grasa sobrepasante con cantidad de maíz energéticamente equilibrado, respectivamente. Según los datos obtenidos en la dieta control, se pueden evidenciar resultados óptimos, como consecuencia de una dieta sin adición de suplementos ricos en grasa respecto a las demás, puesto que la adición de grasas a la dieta genera alteraciones en el metabolismo digestivo (8); la reducción del contenido y la producción de grasa láctea cuando se añaden fuentes de grasa no protegida a la dieta de vacas se ha relacionado con el consumo de materia orgánica fermentable o con la depresión de la digestión ruminal de las paredes celulares (7); en ambos casos se reduce la disponibilidad de acetato y betahidroxibutirato para la síntesis de novo de ácidos grasos en la glándula mamaria (8).

Otras causas propuestas para justificar los efectos negativos observados en respuesta a la inclusión de fuentes de grasa en la dieta de vacas han sido: inhibición de la actividad de la AcetilCoA, Carboxilasa mamaria, por los ácidos grasos preformados o los ésteres acil-CoA (9); ineficiente incorporación de los ácidos grasos poliinsaturados(AGPI) (10) y de los isómeros trans (11) durante la acilación del glicerol; captación mamaria reducida de los ácidos grasos de cadena larga en presencia de AGPI de 20 y 22 carbonos, posiblemente por la inhibición de la lipoproteinlipasa, o competencia por el lugar de acilación en el glicerol.

El contenido de proteína no fue diferente entre T1, T2 y T3; estos valores posiblemente estén relacionados con la degradación de la proteína aportada tras el suministro en dietas ricas en lípidos, especialmente aquellos no protegidos. De esta forma, si los lípidos no son completamente inertes a nivel ruminal, y sobre todo cuando los ácidos grasos son insaturados, se pueden producir 
Efecto de la suplementación con alimentos ricos en ácidos grasos sobre parámetros productivos y composicionales de la leche bovina

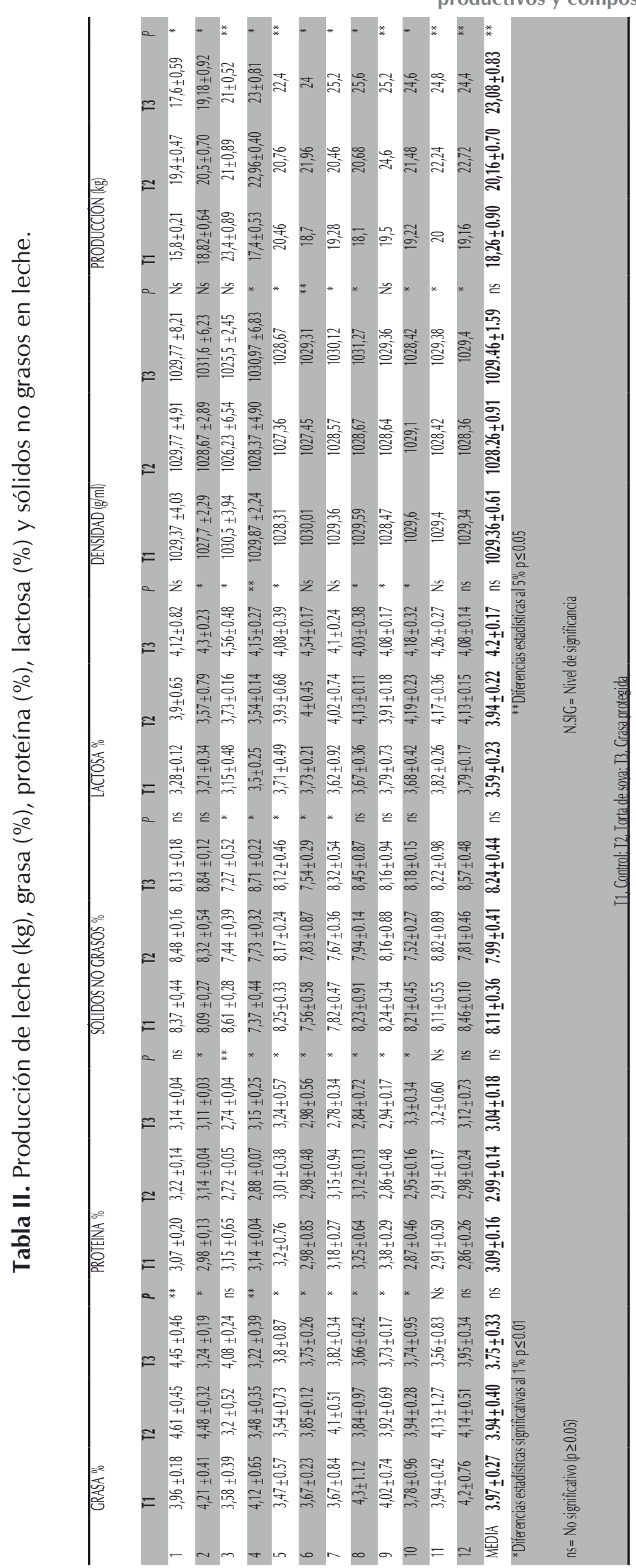

Ciencia y Agricultura Vol. 11 - No. 2 - Julio - Diciembre 2014, p.77-82 ISSN 0122-8420 - 81 
efectos negativos sobre la fermentación ruminal, con disminución en la digestibilidad de la fibra. Ante un posible efecto negativo del aporte de lípidos no protegidos adecuadamente podría esperarse, junto con una menor digestión ruminal de la FDN, un aumento en las proporciones de ácido propiónico $(\mathrm{C} 3)$, una disminución en la proporción de ácido acético (C2) y deácido butírico y una menor concentración total de AGV. Estos efectos a nivel ruminal resultan predisponentes a una disminución del consumo, de la producción de leche y del tenor proteico de esta (7).

\section{Conclusiones}

No se evidencio diferencia en el contenido de sólidos no grasos entre T1, T2 y T3; esto debido a que no se presentaron valores entre los contenidos de proteína, grasa y lactosa; así mismo, se menciona que el porcentaje de sólidos no grasos en la leche disminuye con el número de lactaciones y con la edad de las vacas.

Se evidencia un resultado inversamente proporcional entre producción de leche/kg/día y porcentaje de grasa y proteína. Así mismo, Bailey (1952) afirma que el aumento de la producción de leche se asocia generalmente con una disminución del porcentaje de grasa, proteína cruda, caseína, lactosa, sólidos no grasos y cuerpos sólidos totales.

\section{Referencias}

(1) Gagliostro, G., \& Schroeder, G. (2007). Efectos de la suplementación con sales cálcicas de ácidos grasos insaturados sobre la digestión ruminal en vacas lecheras en pastoreo. Archivos Latinoamericanos de Produccion Animal, 15.

(2) Elizondo, J. (2002). Estimación lineal de los requerimientos nutricionales del NRC para ganado de leche. Agronomía Mesoamericana, 41-1.

(3) Bernall, J. H., \& \& Serna, C. M. (1989). El modelo animal y su comparación con otras ayudas de selección, para producción de leche. Revista facultad agronomia nacional, 51-64.

(4) Venturoso, R. C., \& Almeida, K. E. (2007). Determination of the physical-chemical composition of dairy products: exploratory study to compare the results obtained by classic methodology and by ultra-sound. Revista Brasileira de Ciências Farmacêuticas, 607-613.

(5) Robb, E., \& Chalupa, W. (1987). Lactational responses in early lactation to calcium salts of long-chain fatty acid. Journal of Dairy Science, 220-229.

(6) Ruegsegger, G., \& Schultz, L. (1985). Response of High Producing Dairy Cows in Early Lactation to the Feeding of Heat-Treated Whole Soybeans. Journal of Dairy Science, 3272-3179.

(7) Palmquist, D. (1991). Influence of source and amount of dietary fat on digestibility in lactating cows. Journal of Dairy Science, 1354-1360.

(8) Chilliard, Y., \& Ferlay, A. (2007). Rumen biohydrogenation and nutritional quality of cow and goat milk fat. European Journal of Lipid Science and Technology, 828-855.

(9) Vernon, R., \& Flint, D. (1988). Lipid metabolism in farm animals. Proceedings of the Nutrition Society, 287-293.

(10) Hansen, H., \& Knudsen, J. (1987). Effect of exogenous long-chain fatty acids on lipid biosynthesis synthesis in dispersed ruminant mammary gland cells: esterification of long-chain exogenous fatty acids. Journal of Dairy Scienece, 1344-1349.

(11)Gaynor, P. (1994). Milk fat yield and composition during abomasal infusion of cis or trans octadecenoates in Holstein cows. Europa Journal Lipids Technology, 157-165. 